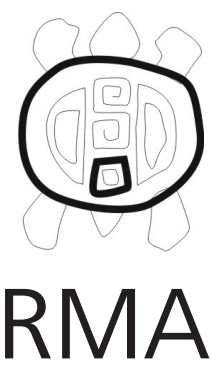

Dossier

\section{Osvaldo Heredia: los proyectos de investigación, el aula y otros contextos de instrucción en la arqueología de los '60 y '70}

Mirta Bonnin

Museo de Antropología, Facultad de Filosofía y Humanidades, Universidad Nacional de Córdoba / CONICET.

E-mail: mbonnin@ffyh.unc.edu.ar / mirtabonnin@yahoo.com.ar

\title{
Resumen
}

Este trabajo se centra en la trayectoria del arqueólogo Osvaldo Heredia, particularmente en los enfoques teóricos, los proyectos de investigación, la tarea docente y las preocupaciones políticas. Ubicado habitualmente dentro de la línea teórica de Alberto Rex González y sus innovadoras perspectivas sobre el noroeste argentino, se analiza la trayectoria de quien fue a su vez una figura notable en el contexto cordobés de los tumultuosos años '60 y '70. A partir de los materiales del Fondo Documental "Osvaldo Heredia" y de entrevistas con sus contemporáneos - tanto colegas como alumnos - se explora la pluralidad de aspectos que hicieron de Heredia parte de un linaje dentro del cual llegó a diferenciarse. Aunque el período en cuestión va desde los '60 hasta su regreso a la Argentina en la etapa democrática, este artículo se concentra mayormente en las investigaciones arqueológicas que Heredia llevó a cabo en el período 1973-1976 y que fueron un punto de inflexión en su pensamiento, con todos sus alcances y, también, sus limitaciones.

Palabras clave: Osvaldo Heredia, arqueología, teoría, Córdoba.

Osvaldo Heredia: research projects, classroom and other instructional contexts in the archaeology of the '60s and '70s

\begin{abstract}
This work focuses on the trajectory of the archaeologist Osvaldo Heredia, particularly in the theoretical approaches, research projects, the task of teaching and political concerns. Usually located within the theoretical line of Alberto Rex González and his innovative perspectives on the Argentine northwest, discusses the history of who was himself a notable figure in the context of the tumultuous Cordoba '60s and '70s. From materials of the Documentary Fund "Osvaldo Heredia" and interviews with his contemporaries - both colleagues and students - explores the plurality of aspects that Heredia made part of a lineage within which came to differentiate. Although the period in question runs from the '60s until his return to Argentina in the democratic era, this article focuses primarily on Heredia archaeological investigations conducted in the period 1973-1976 which were a turning point in his thought, with all its scope and also its limitations.
\end{abstract}

Keywords: Osvaldo Heredia, archaeology, theory, Córdoba.

El desarrollo de la arqueología argentina suele ser organizado en base a planteos que anclan en los períodos políticos, los que ciertamente han marcado fuertes límites en la academia. Sin embargo, al cambiar la escala de análisis y enfocarse en líneas de trabajo concretas es posible diversificar estas interpretaciones. Este trabajo se centra en la trayectoria del arqueólogo Osvaldo Heredia, particularmente los enfoques teóricos, los proyectos de investigación, la tarea docente y las preocupaciones políticas en las décadas de 1960 y 1970. Osvaldo Heredia es ubicado habitualmente dentro de la línea instaurada por Alberto Rex González y sus innovadoras perspectivas sobre el noroeste argentino, la que tuvo algunos movimientos internos de identificación y también de diferenciación, encarnados por sus más dilectos discípulos. Se analizan esos movimientos a la luz de un proceso de formación continua de uno de esos discípulos, O. Heredia, quien fue a su vez una figura notable en el contexto cordobés de los tumultuosos años '60 y '70.

Valiéndonos de los materiales del Fondo Documental "Osvaldo Heredia" depositados en el Archivo del Museo de Antropología de la Facultad de Filosofía y Humanidades, Universidad Nacional de Córdoba (de aquí en adelante FDOH), y de entrevistas con sus contemporáneos - tanto colegas como alumnos - exploraremos la pluralidad de aspectos que hicieron de Osvaldo Heredia parte de un linaje dentro del cual llegó a diferenciarse. Aunque el período en cuestión va desde los '60 hasta su regreso a la Argentina en la etapa democrática, este artículo se concentra mayormente en las investigaciones arqueológicas que Heredia llevó a cabo en el período 1973-1976 y que fueron un punto de inflexión en su pensamiento, con todos sus alcances $y$, también, sus limitaciones. 


\section{El proyecto Ambato}

Hasta la década del '70, el Valle de Ambato era un territorio arqueológicamente virgen, solo abordado esporádicamente produciendo objetos aislados que se presentaban en museos públicos o, mayormente, integrando colecciones particulares reunidas a través del saqueo sistemático. En mayo de 1973 José A. Pérez Gollán y Osvaldo Heredia lo recorrieron por primera vez en un viaje de reconocimiento. Hicieron luego cinco campañas más llevando a cabo prospecciones y excavaciones en ocho sitios entre 1973 y 1976 . La primera denominación que tuvo este proyecto fue "Investigaciones arqueológicas en los Valles de Catamarca y de Singuil"2 y fue presentado a la Facultad de Filosofía y Humanidades de la UNC, junto con un presupuesto de gastos para el trabajo de campo. Su importancia residía en la peculiaridad de las piezas conocidas, en particular los materiales eran Aguada, pero sobre todo en las formas y rasgos técnicos que eran diferentes a los considerados "clásicos". Los hallazgos de los "aficionados" de Córdoba y Catamarca en excavaciones clandestinas, habían localizado sitios arqueológicos dentro de la localidad de Los Varela y Singuil (Dpto. Ambato, Catamarca). Precisamente el huaqueo era un poderoso justificativo para estudiar esta región desde una metodología científica que salvaría la destrucción de un importante material arqueológico que presentaba además un alto interés museístico. Por otro lado, y quizás considerado más importante, la realización de trabajos sistemáticos permitiría establecer una secuencia que contuviera una serie de contextos culturales correspondientes a facies arqueológicas muy poco o nada conocidas en cuanto a sus patrones de poblamiento, hábitos funerarios o economía de subsistencia:

Un plan metódico como el que proponemos contribuirá, a no dudarlo, en forma muy clara y definida al conocimiento de una de las culturas más importantes por su desarrollo tecnológico y artístico que habitara el N.O. argentino; cultura que sirve de hito o jalón demarcador en la secuencia y el proceso histórico de las etnías autóctonas de nuestro país 3 .

Nociones claves en el pensamiento y la práctica de la línea de la historia cultural tales como "cultura", "contexto cultural", "secuencia", "facies", "patrones de poblamiento", "costumbres mortuorias", así como el énfasis en los aspectos tecnológicos y artísticos de la cerámica, le otorgan al enfoque de este proyecto una adscripción definida a un modo de hacer arqueología inaugurado por Alberto Rex González en la Argentina (González 1955,

\footnotetext{
${ }^{1}$ En el viaje de 1974 que A.R. González hace al Ambato localiza el sitio Iglesia de los Indios, que excavará en años siguientes y que posteriormente legará a Inés Gordillo. Esto es interesante en tanto definirá la constitución de dos grupos de trabajo diferentes realizando actividades arqueológicas a pocos metros uno de otro.

2 Manuscrito "Prospección arqueológica intensiva en el departamento Ambato (Provincia de Catamarca)". FDOH.

3 Idem.
}

1960, 1963a, 1963b, 1965, 1979, 1980, 1999) y que sus discípulos adoptaron para enmarcar sus propios trabajos (Heredia 1968). Según Politis y Pérez Gollán (2004), González amplió y sistematizó la secuencia cultural, y obtuvo una cronología absoluta que quizás constituya el mejor ejemplo de la arqueología historicista cultural norteamericana en Latinoamérica, a partir de las ideas de Bennett y sus coautores en el área (Bennett et al 1948).

En el Informe ${ }^{4}$ sobre la campaña de octubre/noviembre de 1973, Heredia describía los trabajos de campo en varios sitios de Ambato, incorporando una forma de relato organizado alrededor de las características arquitectónicas de los asentamientos, descubiertas por detalladas excavaciones horizontales extensas. La preocupación era obtener un panorama amplio que permitiera registrar la distribución de los materiales en relación a los pisos y a las paredes de los recintos. Los sitios se ordenaban cronológicamente en base a sus contenidos materiales, especialmente por las frecuencias de tipos cerámicos claves. Heredia problematizaba la arqueología del Valle de Ambato vinculándola al esquema cronológico cultural definido por González para el Noroeste argentino (González 1955, 1962) la ocupación Condorhuasi, la ausencia de Ciénaga, la unión Condorhuasi y Aguada, las probables influencias de Alamito, la relación con la cultura Las Mercedes de Santiago del Estero por el uso de pintura postcocción en la cerámica, la ausencia casi total de cerámica Aguada polícroma pintada. Por todo ello, era posible pensar que en Ambato se registraba una etapa cronológica y cultural temprana de Aguada, considerando que era necesario encarar la investigación sin preconceptos y atento a las manifestaciones regionales que en Ambato eran muy fuertes.

La centralidad de los tipos cerámicos como marcadores culturales (Condorhuasi, Ciénaga, Aguada polícroma pintada), las influencias como factores relevantes en la definición de la cultura y la idea de fase que subyace detrás de la etapa temprana de Aguada, son categorías características de los trabajos realizados desde el enfoque de la historia cultural. Pero ¿a qué se refería Heredia al plantear que debía iniciarse la investigación sin preconceptos? ¿Acaso a cierta disconformidad con las nociones culturalistas? Dos temas podrían ser significativos y reaparecerán en el trabajo publicado en Relaciones en 1975: los preconceptos y lo regional. Allí Pérez y Heredia publicaban un primer informe de sus investigaciones ${ }^{5}$ con el propósito de presentar los hallazgos más relevantes y comentar algunas hipótesis provisorias surgidas en el

\footnotetext{
4 Manuscrito FDOH.

${ }^{5}$ En el año 1974, el equipo había presentado dos trabajos al III Congreso de Arqueología Argentina reunido en Salta, cuyas actas nunca se publicaron, en principio por efecto de la devaluación de los fondos producida por la crisis inflacionaria llamada el "Rodrigazo", ocurrida pocos meses después del Congreso, y luego porque los manuscritos completos que se encontraban en la imprenta de la Biblioteca Popular Constancio C. Vigil de Rosario, desaparecieron al ser intervenida y desmantelada por los militares en 1976 (Tarragó 2003).
} 
curso de las investigaciones desde 1973, sin pretender llegar a conclusiones debido a que el trabajo se hallaba en curso. En una primera mirada se puede observar que la organización de este escrito tenía puntos en común y otros diferentes de los trabajos que esta línea teórica había publicado hasta el momento. En las publicaciones de entonces era habitual una introducción que incluyera la descripción de las características culturales y fisiográficas de la subárea, la historia de las investigaciones, y luego el patrimonio material de la cultura tratada. Esto solía incluir el patrón de poblamiento y las habitaciones, funebria, economía, tecnología (cerámica, tejeduría, metalurgia), creencias, adornos, arte y cronología (ver González 1961-1964). Dentro de la tecnología cerámica se describían los tipos cerámicos, fundamentalmente a través de las características de la pasta, la superficie y la forma ${ }^{6}$. Aquí la descripción de los sitios era la vía de entrada para luego detallar las técnicas de excavación, los hallazgos en relación a las estructuras y la adjudicación de funcionalidad a los recintos, fundamentalmente por la presencia de determinados tipos cerámicos que no describían en esta publicación por considerar que no correspondía. En este aspecto, las categorías manejadas respecto a lo particular de Ambato se entendían siempre en relación a la entidad "Aguada" (Pérez y Heredia 1975:62).

Sin embargo, y aún como hipótesis, los autores problematizaron la categoría "cultura", de importancia central en las construcciones arqueológicas del NOA, enraizada en el poderoso esquema brindado por González (1955, 1962). En relación a la aparición de nuevos tipos Condorhuasi en Ambato pensaban que específicamente las culturas tempranas se habrían manifestado como comunidades que ocuparon y explotaron distintos espacios, cada una con matices diferenciales, y que aun cuando participaban de una cultura común, presentaban variantes -a veces probablemente significativas- en su patrimonio. (Pérez y Heredia 1975:66). En particular, entendían que la transformación social iniciada en Ambato alrededor del 400/500 d. C., ocurrida en un tiempo relativamente corto en un marco económico productivo de pastoreo previo e incorporando una nueva variedad de maíz (Zea mays) de más alto rendimiento, se había operado en un cambio en las relaciones internas de las comunidades. Esto fue un cambio cualitativo que abrió el camino para el pasaje a una cultura distinta -Aguada- la que posteriormente tal vez por su efectividad económica, ocupa otros ambientes y adquiere notable preponderancia (Op. cit. 1975: 67).

Un aspecto en el que se materializaba este cambio era en la representación del felino como reflejo iconográfico de las relaciones internas de esa sociedad en la que comenzaban a diferenciarse grupos de estatus incipientes, principalmente los guerreros-sacerdotes que asumían la dirección de la comunidad por apropiarse del excedente económico, lo que a su vez posibilitaba una explotación más efectiva del medio ambiente. En este punto cobraban sentido los sitios Iglesia de los Indios y Bordo de los Indios, como expresión del estatus del grupo de guerrerossacerdotes, o como parte de una tradición andina de organización dual. Finalmente reaparecían las categorías culturalistas cuando los autores arriesgaban que Ambato fuera el foco de origen de la cultura Aguada y que en esa época cristalizaran las influencias de Tiwanaco, retomando el problema de los orígenes y las influencias, tan característicos de esta escuela y que habían definido una línea de trabajo desde los años 50 y 60 (ver González 1961-1964: 238 y 247-248; Tarragó 1968:121-122; Heredia 1968:451).

Esto se apoyaba en los aspectos tipológicos de los materiales pero también en los religiosos. La similitud de ideas con otras culturas andinas, aunque no de formas, indicaban un "ciclo definido y culturalmente estabilizado" (González 1961-1964:236). En el polimorfismo que adquiría el felino se jugaba todo un núcleo de ideas fijadas que representaban un importante papel cultural en lo religioso.

La pregunta por el origen o las raíces era también central en la definición de las culturas. Para ello era fundamental contar con marcos cronológicos absolutos y con conocimientos sobre la propia cultura en estudio y de áreas más amplias. Como línea general González adelantaba en 1961-64 que, a modo de hipótesis, "podríamos imaginar un centro, posiblemente en Bolivia, no conocido aún, desde donde irradiaron influencias que, por un lado cristalizaron a orillas del Titicaca, y por otro, alcanzaron, independientemente, el N-O argentino" (González 1961-1964:251).

Tuvo que existir un momento de comienzo en que las ideas y elementos que la integran empiezan a infiltrarse en el N.O., luego un momento de auge y estabilización de la cultura, por último, uno de desintegración. (González 1961-1964: 232)

\section{Hipótesis y notas}

En "Hipótesis y notas", un manuscrito de 1976, Heredia desplegaba una serie de ideas sobre el lugar del ritual en Ambato $^{7}$. Los primeros puntos se referían a la necesidad de buscar indicadores que permitieran determinar el papel de los objetos en el pasaje de una religión familiar a una comunal, tanto a nivel individual, familiar, de la sociedad y de la comunidad, restringidos a un segmento social acotado por edad, sexo o estatus. Los correlatos materiales de estos indicadores eran de tres tipos: I) estructuras, rasgos y artefactos que actuaron probablemente en los rituales públicos a nivel de la comunidad, o todavía más allá; II) rasgos y artefactos que actuaron probablemente en el ritual a nivel familiar o de

\footnotetext{
${ }^{6}$ Con algunas leves variantes este es el patrón de escritura del trabajo de La Candelaria de Osvaldo Heredia de 1968 (Heredia 1968).
}

${ }^{7}$ Manuscrito FDOH. 
la sodality; ; II) artefactos que actuaron probablemente en el ritual personal. Concebía el ritual como punto de articulación entre la religión y los procesos sociales o socio-ambientales.

Aguada como cultura típicamente Formativa... se presenta como una sociedad en la que el poder político está poco desarrollado. De esta manera, como un mecanismo de ordenamiento de la sociedad incrementada en número según lo indica la profusión de asentamientos, fue necesario que las directrices de las autoridades fueran obedecidas para mantener el poder y el orden. Así la religión (con sus proposiciones sagradas, sus rituales, la experiencia religiosa) surge como el mecanismo que disciplina la conducta de los miembros de la sociedad ${ }^{9}$.

A partir de este enunciado Heredia deducía dos hipótesis: una, que en Ambato no había un poder político suficientemente elaborado, y otra que, como consecuencia de lo anterior, surgió y se consolidó un poder religioso en sustitución y como mecanismo ordenador de la sociedad. Como resultado, las conductas de los individuos se hacían "previsibles" y además se establecían "valores" santificados (al modo de la "ética protestante" de Weber), al igual que instituciones y personas, que así adquirían legitimidad. Un tipo particular de mensaje apto para recibir santificación era el de las convenciones sociales que se ocupaban de los asuntos económicos, como por ejemplo el modo por el cual se distribuían las mercaderías entre los miembros de un grupo social, lo que podía ser arbitrario pero también decisivo para el funcionamiento regular de la sociedad.

\section{Desde el exilio}

El Informe ${ }^{10}$ de 1976 fue concluido por Heredia ya en el exilio brasilero. Hacía un recorrido de las tareas llevadas a cabo en Ambato y recordaba las hipótesis que fueron surgiendo y trabajando en los tres años del proyecto. Remarcaba la fuerte percepción que tenían (él y José $A$. Pérez Gollán) de estar frente a una variación regional de Aguada diferente de lo conocido para Hualfín y el Norte de La Rioja y bastante más cercano a Alamito. Dejaba claro que el fin último del proyecto había sido "reconstruir la historia de la ocupación prehistórica del área". El problema cronológico persistía por la falta de fechados, lo que se compensaba con asignaciones de temporalidad a los tipos cerámicos (Condorhuasi, Ciénaga y Aguada). Estaba convencido de que en Ambato se había producido una ocupación temprana de los faldeos orientales para luego avanzar en el fondo del valle.

\footnotetext{
8 Elman Service (1962) describe "sodality" como una "nonresidential association that has some corporate functions or purposes."

9 Manuscrito FDOH.

10 “Investigaciones arqueológicas en Los Castillos - Departamento Ambato - Provincia de Catamarca". FDOH.
}

Aparentemente solo con los incentivos que determinaron la irrupción de la sociedad Aguada se fue haciendo necesario, en un proceso "dialéctico", la explotación más intensiva del suelo y seguramente también una intensificación del aprovechamiento de los recursos. Desde luego el nivel de desarrollado tecnológico debió ser cualitativa y cuantitativamente superior.

De esta extensa reflexión que el mismo Heredia realizaba en 1976 surgía, finalmente, una idea de mayor complejidad y cualitativamente diferente en términos de lo que se venía planteando sobre la evolución social. Proponía trabajar en el futuro estimando la población antigua y estableciendo el patrón evolutivo de las viviendas con las implicancias en la organización social. Esto significaba trabajar las diferencias jerárquicas de los sitios y de sus habitantes en términos superestructurales.

Aunque once años después que los trabajos de campo en Ambato fueran interrumpidos, con los exilios y otras pérdidas en el medio, se puede poner un fin a esta etapa con el trabajo de Pérez Gollán y Heredia "Hacia un replanteo de la cultura de La Aguada", publicado en 1987. En este artículo daban testimonio de los "años de plomo del llamado "Proceso", que había producido la ausencia involuntaria del equipo de trabajo del Proyecto Ambato. Los doce años transcurridos desde esa interrupción hacían posible y necesario formularse nuevas preguntas y plantearse una revisión profunda de algunos conceptos "en torno a lo que se ha dado en denominar cultura de La Aguada" por González en 1961-64. Cuestionaban la difusión y creían que se debía enfocar el problema teniendo en cuenta la dinámica de las relaciones regionales y el intercambio de bienes y recursos.

Creemos que hoy día existen elementos de juicio como para concebir lo que fuera denominado "cultura de La Aguada" (en realidad el Período Medio de González y Pérez (1976: 74) que era caracterizado, fundamentalmente, por Aguada como receptora de las influencias tiwanakotas) como un momento de unificación de carácter social e ideológico. (Pérez Gollán y Heredia 1987: 172).

Era este un nuevo orden en el que se integraban las sociedades locales que ya poseían los elementos materiales y simbólicos enraizados en un antiguo núcleo mítico ideológico surandino compartido.

Al describir la base empírica de sus ideas parecen usar categorías de carácter operativo, habituales en la práctica culturalista pero que también pueden entenderse como aquellas que definen la infraestructura, y que luego se vincularán con otro tipo de categorías, interpretativas, relacionadas con los procesos regionales y el intercambio, la superestructura. En todo caso se trataba de un tiempo histórico en que operaba un proceso de integración regional de gran parte del NOA, de carácter socio-económico 
e ideológico que incidió en los modos de vida de diversas sociedades locales.

Los datos relevados y registrados hasta ahora... nos permiten afirmar que el Valle del Ambato constituyó el centro de origen de lo que González definió, en cronología y contexto para otra área del NOA., como cultura de La Aguada... Fue en esta región del Ambato donde se consiguió formalizar una nueva estructura socioeconómica $e$ ideológica específica que resultó de la conjunción de una serie de procesos ya en marcha, pero que son retomados y modificados, o bien de otros que se elaboran internamente por primera vez y que, con posterioridad, constituirán un factor de integración regional para gran parte del NOA. (Pérez Gollán y Heredia 1987:167).

Al establecer otros vínculos sociales (sobre todo en Alamito por la relación con Condorhuasi), se desembocó en el establecimiento de una vida aldeana mucho más compleja, que luego se extendería por el resto de las regiones clásicas Aguada. Pérez y Heredia planteaban la necesidad de estudiar más la incidencia de la producción en relación con el aumento de la población:

Como aspectos intimamente ligados e inseparables de un proceso social totalizante...hay que considerar el advenimiento de una nueva modalidad de organización social, la elaboración de un sistema ideológico complejo que se nutría de una antigua tradición surandina, un aumento considerable de la población y la construcción de sistemas de riego más amplios y complejos que abrieron la posibilidad de poner bajo cultivo las tierras Ilanas del fondo del valle. Aunque no podamos afirmarlo taxativamente, es válido pensar que a partir de este momento se incrementó una dinámica que, en corto tiempo, modificó las relaciones de producción. Parecen haber indicios que en esta época se abandonaron las antiguas formas de producción orientadas a la autosuficiencia del grupo familiar, para adoptar modalidades más complejas y comunitarias, que hicieron posible la existencia de un excedente económico sobre el que se sustentó ese inédito despliegue de ceremonialismo. (Pérez Gollán y Heredia 1987: 172-173).

Categorías como modo de vida, relaciones de producción, formas de producción, se enmarcan en una línea de pensamiento marxista que caracterizó Lumbreras en su libro La Arqueología como Ciencia Social (1974). Pero además incorporan otro aspecto que la Arqueología Social Latinoamericana (Lorenzo et al. 1976), seguiría discutiendo y que vincula el conocimiento arqueológico del pasado con el presente, principalmente con las historias de los pueblos indígenas americanos. Los autores sostenían que la ideología que cristalizó en el valle de Ambato persistió en las sociedades indígenas posteriores y que sirvió de sustento a las rebeliones anticoloniales que estallaron en el NOA en los siglos XVI y XVII.

\section{La cátedra}

Al mismo tiempo que desarrollaba el proyecto en Ambato, Heredia dictaba clases a estudiantes de primer año. Entre 1971 y 1975 tuvo a su cargo la Cátedra de Prehistoria y Arqueología Americana en la Carrera de Historia de la Facultad de Filosofía y Humanidades de la Universidad Nacional de Córdoba. El programa de 1973 - y de forma parecida el de 1974 - estaba conformado por el plan de teóricos, el de trabajos prácticos y la bibliografía. Los temas teóricos eran la antropología, sus divisiones, los métodos de datación, el poblamiento americano, los comienzos de la producción de alimentos, arqueología de Perú y del Noroeste argentino, las divisiones ecológico-culturales, las culturas, los períodos temprano, medio y tardío, los incas y las rebeliones indígenas. Los prácticos se organizaban sobre cuatro temas: los orígenes de la civilización, la evolución, el paleolítico ${ }^{11}$, y una introducción a la arqueología. La bibliografía incluía textos de autores de distintas procedencias geográficas y teóricas, abarcando manuales sobre el trabajo de campo, métodos de datación, origen del hombre y prehistoria general (v.gr. Almagro Basch 1967), introducción a la antropología (v.gr. Beals y Hoijer 1972), trabajos más técnicos (v.gr. Bordes 1947), otros más teóricos que trataban modelos de evolución social (v.gr. Childe 1954, 1958, 1972). Incluía el trabajo de Betty Meggers y Clifford Evans, Como interpretar el lenguaje de los tiestos ${ }^{12}$ pero también introducía textos de nuevas tendencias en Arqueología como el de David Clarke, Analitical Archaeology (1968), de Kent Flannery, La ecología de la producción temprana de alimentos en Mesopotamia (1965), Robert MacNeish (1971). Además incorporaba bibliografía sobre la arqueología del noroeste argentino de autores como González, Cigliano, Núñez Regueiro, Pérez, Krapovickas, Madrazo, Márquez Miranda, Montes y de él mismo. Tenía especial tratamiento en los prácticos el texto De los Pueblos, las Culturas y las Artes del Antiguo Perú de Luis Lumbreras (1969), arqueólogo enrolado en la Arqueología Social Latinoamericana $^{13}$. La cátedra editaba el material de lectura para uso exclusivo de los alumnos, incluyendo los 22 textos considerados básicos para los teóricos y para los prácticos ${ }^{14}$, estando todos en castellano ya que

\footnotetext{
11 Del programa de prácticos eliminó los puntos sobre el paleolítico y avanzó sobre las etapas de organización socio-política de Perú y Mesoamérica, utilizando el esquema de Bennett y Bird de 1949, aún cuando aclaraba que sentía que expresaba mejor la situación de los Andes Centrales que las etapas mesoamericanas.

12 Esta era una traducción realizada por Víctor Núñez Regueiro durante su estadía en el Smithsonian con Meggers y Evans a fines de 1960. Se enseñaba en este texto el paso a paso para hacer las seriaciones cerámicas.

13 Luis Lumbreras De los Pueblos, las Culturas y las Artes del Antiguo Perú, editado por Moncloa-Campodónico en Lima, 1969. Mimeografiado casi totalmente en el tomo 2 del material de cátedra.

14 "Prehistoria y Arqueología Americana", Tomos 1 y 2, Ediciones Dato.
} 
Heredia realizaba las traducciones.

En este período, la cátedra era uno de los espacios más formativos e inclusivos de los estudiantes del Departamento de Historia ${ }^{15}$. Los viajes de campaña a Ambato y a otras localidades se hacían con los alumnos de primer año y con los de años anteriores que se habían ido incorporando al equipo, conformando grupos de hasta 28 estudiantes. Hoy esos ex-alumnos la recuerdan como una época divertida y comprometida en la que se establecieron vínculos perdurables. Una frase que se repite en las entrevistas realizadas es "fue la mejor época de mi vida". El "Negro" - como se refieren a Osvaldo Heredia todos los entrevistados - es recordado de manera generalizada con afecto, especialmente por los miembros de la familia de Agustín Seco en la localidad de Los Castillos, donde se alojaban durante las campañas arqueológicas en el Valle de Ambato de Ambato.

Además de sus tareas docentes, Heredia ejerció la Dirección del Departamento de Historia durante dos períodos consecutivos (1973 y 1974), en momentos de gran agitación universitaria en el que muchas de las cuestiones se planteaban y dirimían en la Asamblea, órgano de gobierno del Departamento, presidida también por él. Este desempeño le valió el reconocimiento de los estudiantes y permitió que volcara allí su vena política. Algunos compañeros recuerdan que Heredia decía en las asambleas que representaba a las organizaciones de base y que a veces repartía folletos o cuadernillos de una organización que no recordaban, desconociendo si era miembro de una organización armada o solo un "militante ideológico" 16. Todos reconocían que el "Negro" era alguien que ayudaba, ponía la casa, guardaba cosas u, ocultaba a algún compañero.

Durante su gestión como Director trató de introducir modificaciones en el estatuto del departamento de Historia. En un documento consensuado por docentes y estudiantes hay un diagnóstico que parte de la idea del "aislamiento" de la Universidad, critica la concepción ideológica liberal y reaccionaria de la enseñanza de la Historia en la Facultad, y afirma que la dependencia cultural se manifiesta claramente en el plan de estudios ya que el eje central corre por la historia universal y europea, desplazando "la importancia natural y lógica que la historia contemporánea latinoamericana y argentina debe tener para nosotros" ${ }^{17}$. El enfoque debía centrarse

\footnotetext{
15 En un artículo en este mismo volumen, Germán Soprano señala que las cátedras, aún hoy, constituyen instancias de reclutamiento e incorporación de los estudiantes a los equipos de investigación en arqueología (ver nota 8).

16 Es necesario aclarar que las entrevistas no han sido fáciles de concretar por la resistencia de antiguos colegas y estudiantes a hablar abiertamente de temas relacionados a la lucha política y en especial a la lucha armada, tanto de ellos como de sus compañeros, y de Heredia en particular.

17 Es un documento mimeografiado de 4 hojas, que incluye una introducción de 5 páginas y un anteproyecto de estatuto de la escuela de Historia. FDOH.
}

en la historia americana y argentina, de modo que el estudio de la historia universal y europea se hiciera desde una perspectiva y en función del ámbito latinoamericano:

El replanteo y la reorientación de los contenidos posibilitarán una mejor comprensión de la realidad nacional y latinoamericana, que nos permitirá incidir sobre ella y contribuir efectivamente a poner la universidad al servicio de la liberación de nuestro país $^{18}$.

\section{Heredia antes de Ambato}

¿De dónde traía Heredia los conceptos y categorías utilizadas durante los trabajos en Ambato, que nos hablan de una compleja red de ideas acerca de lo arqueológico y de la práctica del arqueólogo? ¿Acaso formaban parte de sus preocupaciones teóricas en años previos? Para cuando hizo su tesis de doctorado sobre la cultura de la Candelaria (1965 a 1970), la correspondencia con González y Núñez Regueiro es bastante reveladora en este sentido. Desde una típica preocupación culturalista, Heredia le comentaba a González, como su director de tesis, que junto a Víctor Núñez Regueiro, su director de beca en CONICET, querían relacionar culturalmente las áreas de Selvas Occidentales y Chaco Santiagueña "...con el objeto de lograr una vía de dispersión de algunos elementos culturales - fundamentalmente la cerámica...", y así poder lograr una "secuencia horizontal a lo largo de los ríos"19.

Estando González en la Universidad de Harvard en 1968, Heredia le contaba que viajaría a Tucumán para hacer una prospección exhaustiva en los faldeos orientales del Aconquija, y en sucesivos viajes trataría de batir toda la supuesta área de Candelaria, haciendo recolecciones de superficie $y$, eventualmente, algún sondeo estratigráfico con el fin de hacer una buena seriación y definir las áreas de Candelaria ${ }^{20}$. Mientras hacía su tesis doctoral, Heredia se manejaba casi exclusivamente con las categorías de la historia cultural. Para ello contaba con su formación al lado de González a inicios de los 60, y con Núñez Regueiro sobre todo a partir de la experiencia de las campañas a El Alamito. Después de que González renunció al Instituto de Antropología de Córdoba en 1963 y asumió esa dirección Núñez Regueiro éste tendría mayor influencia sobre Heredia. Inclusive luego de la no renovación del contrato de Núñez Regueiro en Córdoba en 1966 y durante su estadía en los Estados Unidos junto a Betty Meggers y Clifford Evans, siguió siendo una fuente de consulta permanente. Núñez Regueiro, en una línea que podríamos clasificar como más ortodoxa, se preocupaba de que Heredia se mantuviera en la línea culturalista, lo que quedaría plasmado en las frecuentes y extensas cartas

\footnotetext{
$18 \mathrm{FDOH}$.

19 FDOH, Correspondencia 13/07/65.

20 FDOH, Correspondencia 06/11/67.
} 
entre ambos ${ }^{21}$, como caso:

Creo que es mejor que a Candelaria, tal como la presentas, no la denomines "cultura" sino "tradición" Candelaria I, II, III y IV; el término facie es correcto para El Mollar, Chuscha, etc., ya que se está utilizando en esa forma en trabajos que por el tipo de materiales (principalmente cerámica) se asemeja con los tuyos, tales como con los trabajos del Brasil22, pero haciendo resaltar que las tales facies son en realidad complejos cerámicos. Eso, en base al esquema que me enviaste; si para cada facie o etapa cultural de Candelaria tenés más elementos (funebria, economía, etc.), el asunto cambia, pero por el momento me parece mejor llamarla tradición que cultura ${ }^{23}$.

Paralelamente, Heredia demostraba inquietudes por temas arqueológicos pero desde enfoques más sociales y no tan estrictamente culturalistas. En una carta de respuesta a González que estaba en Harvard, del 24 de Julio de 1967, Heredia le informaba lo siguiente.

Mi venida a Buenos Aires ${ }^{24}$ me ha significado una serie de ventajas...con Pepe Pérez hemos empezado a trabajar en un tema que, creo, le podemos sacar buen jugo. Queremos intentar la reconstrucción social-política-económica del Período Tardío en el Noroeste.

Para ello planeaban hacer un relevamiento exhaustivo de las crónicas, de la bibliografía arqueológica, visitar sitios ya relevados y no relevados, y quizás realizar sondeos estratigráficos. Consideraban urgente afinar la metodología por lo que estaban leyendo trabajos tales como los de Robert Adams, Braiwood, Wittfogel, Willey, Childe, Steward, Palerm, etc. En la línea de autores materialistas, se estaban preocupando por los problemas teóricos que plantean las grandes obras hidráulicas vinculadas a la agricultura prehispánica sobre

\footnotetext{
21 Otro ejemplo notable es cuando en 1969 Víctor Núñez Regueiro le envía un ejercicio para que resuelva, anexado a una extensa carta abundante en conceptos referidos a la seriación y al método de Ford. En una hoja le mandaba los datos de frecuencias de tipos cerámicos de Alamito, datos que Heredia debía intentar ordenar para producir una seriación. La respuesta correcta iba en un sobre aparte que Heredia debía abrir para verificar si lo había hecho bien.

22 En Brasil fue donde la historia cultural americana echó raíces gracias a las gestiones de Betty Meggers y Clifford Evans quienes fundaron y sostuvieron durante muchos años los programas para investigación regional Programa Nacional de Pesquisas Arqueológicas, PRONAPA y el PRONAPABA, Programa Nacional de Pesquisas Arqueológicas na Bacía Amazónica (Politis y Pérez Gollán 2004). Víctor Núñez Regueiro se integró a este Programa desde 1967 realizando excavaciones en sitios históricos en Corrientes y Misiones (Núñez Regueiro 1975). En ese marco fue con una beca al Smithsonian para procesar sus materiales de Litoral y también de Alamito.

23 FDOH, Correspondencia 10/12/68.

24 En diciembre de 1966, Osvaldo Heredia y Beatriz Alasia de Heredia quedaron desvinculados forzosamente de la UNC y emigraron a Buenos Aires.,
}

la organización social y política:

Sobre todo nos inclinamos por la hipótesis de Charles Adams ${ }^{25}$ y seguidores sobre la existencia primero de un poder centralizado más o menos fuerte y capaz de mover gente, y rechazando lo que piensa Witfogel y seguidores sobre que las sociedades hidráulicas tuvieron primero las acequias y canales y luego, por la necesidad de controlar y distribuir el agua se constituye una clase dominante que conforma el poder centralizado. Vamos a trabajar también con el problema ecológico ya que los campos de cultivo se encuentran muy cerca del pie del nevado de Cachi, con lo que los negros se aseguraban agua durante todo el año y sobre todo con la idea de que ese sitio (Ilamado Las Pailas) fue un centro proveedor de comida de las poblaciones que se encontraban en el valle del río Calchaquí, tales como La Paya, Kipón, y otros restos dispersos que no tienen campos de cultivo (andenes) en sus proximidades.

Núñez Regueiro trataba de reorientarlo ya que consideraba que:

...por ejemplo (esto lo tomo de tu carta) "Qué es primero, el huevo o la gallina?"; es una pregunta mal formulada, ya que ambos (huevo y gallina) surgen conjuntamente como resultado de un proceso evolutivo que dio origen a los ovíparos. Concretamente, como esto se relaciona con Las Pailas y afines, pienso que, como el huevo y la gallina, las grandes obras agrícolas, etc., y un gobierno central más o menos fuerte, surgen paralelamente como resultado de una paulatina complejización tanto en el sistema político como en el económico (agrícola, etc.). Ahí lo que hay que preguntarse no es: "Surgió primero un gobierno fuerte, que pudo movilizar gran cantidad de gente" o "Surgió dicho gobierno como consecuencia de la existencia de un gran centro agrícola", o algo parecido. Lo que hay que preguntarse ahi, en primer lugar, es: "Existe una relación cronológica y cultural evidente entre Las Pailas y La Paya o/y Payogasta?", y entre esa pregunta y la que intentás formular respecto a organización social, política y económica, hay otros cuantos pasos antes de llegar a preguntarse "En que forma se fue complejizando todo el fato hasta dar al final como resultado un gobierno fuerte y un

\footnotetext{
25 Puede que sea Robert M. Adams, que escribe en 1960 "The origin of cities" en Scientific American: " El surgimiento de las ciudades, la segunda gran "revolución" en la cultura humana, fue preminentemente un proceso social, una expresión más de cambios en la interacción del hombre con sus pares que en su interacción con su ambiente". " ... la revolución urbana un cambio cultural y social decisivo que fue menos directamente ligado a cambios en la explotación del ambiente". Robert M. Adams trabajaba en los años 1950 y 1960 desde Chicago en las regiones de Yucatán, México y en el Cercano Este. Le interesaba trabajar en Iraq para continuar el reconocimiento arqueológico en conexión con programas de desarrollo agrícola modernos. Este artículo será traducido por Heredia para sus clases desde 1971
} 
sistema económico complejo?"

Citando a Binford (1964: 427), Núñez R. insistía en que antes de excavar había que hacer diseños de investigación, porque si no se trataba de un crimen, de una falta de ética. En una carta del 14/01/69 le ofrecía hacerle fotocopias del trabajo citado ya que le "parece que hay que tomarlo bastante en cuenta en algunas cosas"26.

\section{La figura de Rex}

La influencia de Alberto Rex González fue decisiva en la formación de Heredia (y de Pepe Pérez Gollán) ${ }^{27}$. En respuesta a una carta de González (24/07/1967), Heredia le trasmitía la preocupación y expectativa de todos por la permanencia del maestro en Estados Unidos:

...comprendemos que lo más probable es que Ud. se quede, pero también hemos llegado a comprender como toda una ciencia en nuestro país dependía y depende de una sola persona.

Seguidamente le contaba que seguían trabajando sobre patrones de poblamiento del Tardío con Pepe y que estaban muy entusiasmados con la posibilidad que abría la visita de Adams a la Argentina de crear un instituto de investigaciones antropológicas y arqueológicas, aunque no sabe los resultados:

Toda la gente que ha estado conectada con Víctor y Pepe Cruz, ve en esto la gran posibilidad de trabajar en Antropología y Arqueología de una manera sistemática y ordenada, bajo la guía de alguien. Nos reconforta aún más el hecho de que la concreción de ese proyecto haga que lo tengamos a Ud. nuevamente con nosotros.

La falta de un guía ya había aparecido en las cartas a González, sobre todo en relación a Candelaria. Surge claramente de la correspondencia de estos años que el traslado del lugar de trabajo (de Córdoba a La Plata) y el cambio de director (de Núñez R. a Cigliano) realizado por Heredia, no era satisfactorio, se sentía fuera del sistema y la relación con Eduardo Mario Cigliano aparecía como una formalidad para continuar en el CONICET. En

\footnotetext{
26 El artículo de Lewis Binford de 1964, "A Consideration of Archaeological Research Design" (American Antiquity 29(4): 425-441) se encuentra fotocopiado entre los papeles de Heredia. Víctor Núñez Regueiro utilizará en sentido positivo bibliografía de este autor y de otros de la Nueva Arqueología en su artículo "Conceptos teóricos que han obstaculizado el desarrollo de la Arqueología en Argentina", Estudios 1, Museo de Cachi, Salta 1972. Politis y Pérez Gollán afirman que para fines de los años 1970 algunas de las ideas pioneras de la arqueología procesual se habían esparcido en Latinoamérica, incluyendo trabajos de Binford, Clarke, Schiffer y Flannery, pese a que las aproximaciones de la historia cultural americana y austríaca eran todavía predominantes (2004).

27 González fue Director del Instituto de Antropología y Titular de la Cátedra Prehistoria y Arqueología de la UNC entre 1957 y 1964. Osvaldo Heredia fue su alumno e integró su equipo de trabajo desde el primer año de la carrera.
}

distintas ocasiones Heredia le transmitió a González las expectativas por su regreso de Estados Unidos:

...después de dos años...Estamos muy anhelantes esperando su llegada. Esta noticia nos ha llegado por "trascendidos", pero no sabemos, en concreto, que validez tiene. Tampoco sabemos si, de venir, lo hará para quedarse definitivamente o para volver a irse poco tiempo después. Yo, personalmente, tengo una buena cantidad de problemas que plantearle; problemas que han ido surgiendo de mis trabajos en Candelaria y que, por no tener con quien consultarlo, me han llevado a postular hipótesis que no se si andan por la buena o por la mala senda... El viaje que pensábamos hacer con Pepe en julio estamos a punto de suspenderlo ante la posibilidad de que Ud. Ilegue en algún día de este mes.

Nos quedamos a la espera de su llegada...vamos a ir poniendo el asado al fuego para que se vaya haciendo despacito hasta que se produzca su llegada y celebrarla ${ }^{28}$.

Según Podgorny et al. (2005), el XXXVII Congreso Internacional de Americanistas de Mar del Plata en 1966, presidido por González, representó un cambio para sus principales organizadores (Núñez R. fue su Secretario General) que consolidaron a la vieja generación por un lado, (Menghin, Imbelloni, Serrano) dándoles reconocimiento honorario como una herencia del pasado; y por otro identificando hacia el futuro las tendencias de los jóvenes investigadores norteamericanos Betty Meggers y Clifford Evans considerados como renovadores y revisores de los viejos conceptos. A estos Rex González les agradecía el afecto por América Latina al apoyar a los estudiantes jóvenes en el Instituto Smithsoniano (Actas Memorias XXXVII CIA 1968: LV). A sus 50 años, González representaba el puente entre las viejas y futuras generaciones, y también la conexión entre las jóvenes generaciones locales y lo que parecía como una promesa de renovación en los Estados Unidos (Podgorny et al. 2005: 65). Así, la presencia de González y sus discípulos en el Primer Congreso de Arqueología Argentina de Rosario de 1970, lo consolidó como organizador y mediador (Podgorny et al. 2005:65). Podríamos agregar que esto ya era evidente en el XXXVII CIA de Mar del Plata (1966) y que más que mediador, González era ya para ese momento el referente fundador de una nueva línea de pensamiento y de práctica de la arqueología del Noroeste, lugar que mantuvo por varias décadas, garantizando la continuidad ante los quiebres producidos por las exoneraciones y relocalizaciones forzadas tanto de él como de sus discípulos (Guber 2006).

\section{Consideraciones finales}

En el corto tramo que implicó el desarrollo del proyecto Ambato entre los años 1973 y 1976, dos conjuntos de

\footnotetext{
${ }^{28} \mathrm{FDOH}$, Correspondencia, 19/06/1968
} 
categorías parecieron ponerse en tensión. Una era la línea de la Historia Cultural de origen norteamericano y la otra la Arqueología Social Latinoamericana. Las categorías que históricamente se han manejado para entender la cultura Aguada en tanto conjunto material complejo, heterogéneo y de amplia distribución territorial y temporal, se han inscripto mayormente dentro de la línea de pensamiento y práctica de la historia cultural norteamericana. Este fue el marco desde donde se plantearon las investigaciones arqueológicas en el Valle de Ambato. El objetivo era entender una manifestación muy particular de aquella cultura tal como se observaba en esa región, principalmente a partir del conocimiento de piezas cerámicas de colección. Tanto Heredia como Pérez eran parte de un modo de pensar y hacer arqueología instaurada por González, quien se había formado bajo el paradigma de la historia cultural norteamericana, y que a su vez los había formado a ellos.

Las categorías historicistas culturales son más visibles en el material publicado o en los manuscritos que se pensaba hacer circular en un ámbito académico, como proyectos e informes que debían ser leídos por pares en instancias de evaluación. Esas categorías habían estructurado los trabajos de Heredia sobre La Candelaria varios años antes. Cultura, tradición, facie, fase, tipo cerámico, así como habitaciones y patrón de poblamiento, funebria, economía, tecnología, creencias, guerra y caza, adornos, arte, narcóticos, son habituales en las publicaciones como subtítulos que organizan y dan contenido al patrimonio de determinada cultura. Esto sumado a la centralidad de las frecuencias de tipos cerámicos como herramientas para proponer secuencias temporales de valor cultural: la historia cultural requiere darle validez real a los tipos alfareros como indicadores cronológicos y culturales.

Por otro lado, los documentos que no fueron redactados para trascender a la comunidad arqueológica, como las cartas, las notas manuscritas, los apuntes de clase, las elecciones bibliográficas y las charlas con los contemporáneos en el aula, en el laboratorio y en las campañas, denotan una mayor libertad para dar opiniones sobre la política y sobre lo arqueológico. Era en ese ámbito donde se registraba una mayor convicción ideológica y una acción correlativa. La correspondencia así como las aulas, el laboratorio y el terreno son lugares menos estructurados en donde se pueden, acaso se deben, poner en discusión ideas arriesgadas, novedosas, más comprometidas. Lejos de la especulación publicable, estas instancias de oralidad suelen ser compartidas con personas sentidas como amigos o compañeros, "gente que piensa como uno" o que es permeable al propio pensamiento. Tratándose del marco social y político de los años 60 y 70, en los que se discutían "latinoamericanamente" las visiones del mundo dominantes, lo social en arqueología era un tema que circulaba en el medio académico como una forma de propuesta política que conjugaba la actividad científica con el compromiso social. Lumbreras (1974) materializaba en su libro esas ideas como una propuesta de trabajo encuadrado en el marxismo, inaugurando así una línea que denominó "Arqueología Social"29. Pero algunos años antes, en el Proyecto Ambato, lo social estaba cada vez más presente en los manuscritos y en el material publicado, aunque se hiciera más evidente en las acciones y compromisos que asumían Heredia y personas de su equipo.

Como categorías de la Arqueología Social Latinoamericana, las de aquellos tiempos no llegaron a ser claras y definidas. Se mezclaron y filtraron en los escritos historicistas culturales, pero no llegaron a trasmitirse como categorías arqueológicas científicas acabadas. Se pusieron de manifiesto como compromiso con lo social en la cátedra, en la formación de los estudiantes, en la militancia política, en la conexión con las comunidades locales, y en parte de la bibliografía que se compartía con los alumnos. Osvaldo Heredia tenía una postura política radicalizada que permeaba su concepción acerca del rol del arqueólogo latinoamericano (Politis y Pérez Gollán 2004). En sus cartas manifestaba una leve crítica de la subordinación teórica de la arqueología en el continente, pero no cuestionaba claramente la epistemología historicista cultural. Se reconocía como parte de la genealogía "Gonzaliana", y entre sus referentes y pares más cercanos estaban otros discípulos de Rex. Además compartía con él y con sus compañeros las preocupaciones políticas y la sensibilidad a las situaciones de injusticia social. Tanto González como sus discípulos siempre estuvieron alineados en una práctica arqueológica progresista y comprometida, y a veces pagaron con la persecución, el exilio y la muerte. Esto nos lleva a pensar que las teorías adoptan matices locales según sus contextos académicos, empíricos y políticos. La epistemología historicista cultural en la Argentina confrontaba con una perspectiva histórico cultural centro-europea, defendida por académicos comprometidos, sí, pero con ideologías de derecha y conservadoras.

Para 1987, el Negro Heredia y Pepe Pérez habían regresado al país y se disponían a repensar Aguada en Ambato. Seguramente influidos por sus aprendizajes en Brasil y en México respectivamente, creyeron que "los arqueólogos vamos construyendo una propia teoría de los indicios que dé cuenta, finalmente, de la utopía" (Pérez Gollán y Heredia 1987:176).

Córdoba, Septiembre de 2010

\section{Agradecimientos}

Este artículo fue preparado para publicación en el marco del PICT/R FONCYT 2006-1728: Antropologías argentinas. Historia y antropología social del campo antropológico en la República Argentina 1940-1980.

\footnotetext{
29 Recordemos que Núñez Regueiro utilizó esta misma denominación (La Arqueología como Ciencia Social) aunque en un sentido algo diferente, en el artículo "Conceptos teóricos que han obstaculizado el desarrollo de la Arqueología en Sud-América", Estudios de Arqueología 1, Museo Arqueológico de Cachi, 1972.
} 
Agradezco especialmente a Beatriz Heredia y a sus hijos Diego y Ana Inés por confiarnos la documentación personal y la biblioteca de Osvaldo Heredia. A Pepe Pérez por enseñarme la importancia de este tipo de arqueología que practicaron con su amigo O. Heredia. A ex-alumnos y colegas de Heredia, en particular a Susana Assandri, Sofía Juez y Juana Aratano por compartir generosamente sus materiales y sus recuerdos sobre el "Negro". A los colaboradores del Archivo del Museo de Antropología, especialmente a Natalia Zabala, por el minucioso trabajo de conservar y ordenar el material del Fondo Documental "Osvaldo Heredia". Finalmente, doy las gracias a Rosana Guber por sus sugerencias para que este trabajo quedara un poco mejor.

\section{Bibliografía}

Actas y Memorias del XXXVII Congreso Internacional de Americanistas. 1968. Mar del Plata, Argentina.

Adams, Mac. R. M. 1960. The origin of cities. En Scientific American, September 1960. California. USA.

Almagro Basch, M. 1967. Introducción al estudio de la Prehistoria y de la Arqueología de campo. Guadarrama.

Beals, R. y H. Hoijer. 1972. Introducción a la Antropología. Aguilar. Madrid.

Bennett, W., C. Bleiler, E. y F. Sommer. 1948. Northwest Argentine archaeology. Yale University Publications in Anthropology 38. New Haven. USA.

Binford, L. 1964. A Consideration of Archaeological Research Design. American Antiquity 29(4): 425-441

Bordes, F. 1947. «Etude comparative des différentes techniques de taille du silex et des roches dures». L'Anthropologie, tome 51 (Páginas 1-29).

Chile, V. G. 1954. Los orígenes de la civilización. FCE. México.

Childe, V. G.1958. Reconstruyendo el pasado. Traducción de M. T. Rabiela de Roque. UNAM. México. 171 p.

Childe, V. G.1972. Introducción a la arqueología. Ariel. Barcelona.

González, A. R. 1961/1964. La cultura de La Aguada del N.O Argentino. En: Revista del Instituto de Antropología, tomo II-III, pp.205-253.

Guber, R. 2006. Linajes ocultos en los orígenes de la antropología social de Buenos Aires. Avá, Revista de Antropología. N 8. Posadas. 26-55.

Heredia, O. 1968. La Cultura Candelaria. En: Ciencia e Investigación, Tomo 24: 10, pp. 434-453. Octubre 1968. Publicada por la Asociación Argentina para el Progreso de la Ciencia; Órgano de Información del CONICET.

Hole, F. y R. F. Heizer. 1965. Introducción a la arqueología prehistórica. FCE. México. 300 pp.

Lorenzo, J. L., A. Pérez Elías y J. García Bárcena. 1976. Hacia una arqueología Social. Reunión en Teotihuacan (Octubre de 1975). Instituto Nacional de Antropología e Historia. México.

Lumbreras, L. 1974. La Arqueología como ciencia social. Ediciones Histar. Perú.

Mac Neish, R. 1971. Early Man in The Andes. Scientific American. Vol 24, $n^{\circ} 4$ : 36-45-

Núñez Regueiro Conceptos teóricos que han obstaculizado el desarrollo de la Arqueología en Argentina, Estudios 1, Museo de Cachi, Salta 1972

Pérez Gollán, J. A. y O. Heredia. 1975. Investigaciones arqueológicas en el Departamento Ambato, Provincia de Catamarca. En: Relaciones, Tomo IX. Sociedad Argentina de Antropología, Buenos Aires, Argentina.

Pérez Gollán, J. y O. Heredia. 1987. Hacia un replanteo de la cultura de La Aguada. En: Cuadernos del Instituto Nacional de Antropología, 12. Buenos Aires, Argentina.

Podgorny, I., Tobías, M. y M. Farro .2005. The Recepción of New Archaeology in Argentina: A Preliminary Survey. En: Global Archaeological Theory. Contextual Voices and Contemporary Thoughts. Editado por P. Funari, A. Zarankin y E. Stovel. Academic Publishers. New York, USA.

Politis, G. y J.A. Pérez Gollán. 2004. Latin American Archaeology: From Colonialism to Globalization. En: Meskell, L. y R. Preucel: A Companion to Social Archaeology. Parte IV, Capítulo 15, pp. 353-373. Blackwell Publishing, USA.

Service, E.1962. Primitive social organization: an evolutionary perspective. Random House, 211 pp.

Soprano, G. 2010. La enseñanza de la arqueología en la Facultad de Ciencias Naturales y Museo de la Universidad Nacional de La Plata. Un análisis sobre el liderazgo académico de Alberto Rex González y Eduardo Mario Cigliano (1958-1977). Revista del Museo de Antropología, N³.

Tarragó, M. 1968. Secuencias culturales de la etapa agroalfarera de San Pedro de Atacama (Chile). En: Tomo II, Actas y Trabajos del XXXVII Congreso Internacional de Americanistas, Mar del Plata 1966, Argentina.

Tarragó, M. 2003. La Arqueología de los valles Calchaquíes en perspectiva histórica. Anales Nueva Época "Local, Regional, Global: prehistoria etnohistoria en los Valles Calchaquíes", University of Goteborg, Suecia. 